Article

\title{
Antibiotic-Resistant Escherichia coli and Sequence Type 131 in Fecal Colonization in Dogs in Taiwan
}

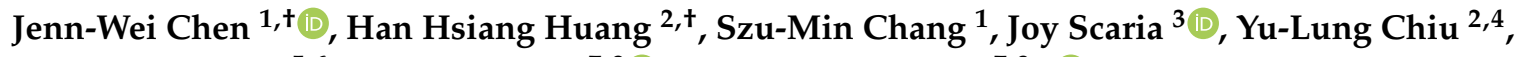 \\ Chih-Ming Chen ${ }^{5,6}$, Wen-Chien Ko ${ }^{7,8}$ (D) and Jiun-Ling Wang ${ }^{7,8, *(1)}$ \\ 1 Department of Microbiology and Immunology, College of Medicine, National Cheng Kung University, \\ Tainan 704, Taiwan; jc923@mail.ncku.edu.tw (J.-W.C.); s5nau3@gmail.com (S.-M.C.) \\ 2 Department of Veterinary Medicine, National Chiayi University, Chiayi City 60054, Taiwan; \\ hhuang@mail.ncyu.edu.tw (H.H.H.); handel737@yahoo.com.tw (Y.-L.C.) \\ 3 Department of Veterinary and Biomedical Sciences, South Dakota State University, \\ Brookings, SD 57007, USA; joy.scaria@sdstate.edu \\ 4 Department of Veterinary Medicine, National Chung Hsing University, Taichung 402, Taiwan \\ 5 Department of Nursing, Jenteh Junior College of Medicine, Nursing and Management, Miaoli 356, Taiwan; \\ chioming2002@yahoo.com.tw \\ 6 Department of Internal Medicine, Tungs' Taichung MetroHarbor Hospital, Taichung 435, Taiwan \\ 7 Department of Internal Medicine, National Cheng Kung University Hospital, Tainan 701, Taiwan; \\ winston3415@gmail.com \\ 8 Department of Medicine, College of Medicine, National Cheng Kung University, Tainan 701, Taiwan \\ * Correspondence: jiunlingwang@gmail.com; Tel.: +886-6-2353535 \\ + These authors contributed equally to this work.
}

Received: 16 August 2020; Accepted: 18 September 2020; Published: 20 September 2020

\begin{abstract}
Background: Most drug-resistant Escherichia coli isolates in dogs come from diseased dogs. Prior to this study, the prevalence and risk factors of fecal carriage drug-resistant $E$. coli and epidemic clone sequence type (ST) 131 (including subtypes) isolates in dogs were unknown. Methods: Rectal swabs were used for E. coli isolation from 299 non-infectious dogs in a veterinary teaching hospital in Taiwan. Antibiotic resistance and multiplex PCR analyses of E. coli for major STs were performed. Result: There were $43.1 \%$ cefazolin-resistant, $22.1 \%$ fluoroquinolone-resistant, and $9.4 \%$ extended-spectrum beta-lactamase-producing $E$. coli in our cohort. In the phylogenetic study, B2 was the predominant group (30.1\%). The cefazolin-resistant group and ciprofloxacin-resistant group had greater antibiotic exposure in the last 14 days $(p<0.05)$. The age, sex, and dietary habits of the antibiotic-resistant and -susceptible groups were similar. In the seven isolates of ST131 in fecal colonization, the most predominant subtypes were FimH41 and FimH22. Conclusion: Recent antibiotic exposure was related to the fecal carriage of antibiotic-resistant $E$. coli isolates. Three major subtypes (FimH41, H22, and H30) of ST131 can thus be found in fecal carriage in dogs in Taiwan.
\end{abstract}

Keywords: dog; ST131; ESBL; fecal colonization; Escherichia coli

\section{Introduction}

The close bond between humans and their dogs provides opportunities for the exchange of multidrug-resistant organisms. Moreover, the clinical infection of extended spectrum beta-lactamase (ESBL)-producing Escherichia coli in companion animals has been reported [1,2]. ESBL-producing E. coli have been reported since the late 1990s in companion animals in south-European countries and have now become widespread, with many nosocomial outbreaks in dogs in recent years [1,3]. Surveillance for antimicrobial resistance among bacteria isolated from dogs is useful for guiding antibiotic use when treating canine infections [2,4-6]. The urinary tract disease guidelines for dogs suggest that 
veterinarians should be aware of the pathogen and antimicrobial resistance trends among urinary pathogens isolated from patients in their clinic [7].

The prevalence of ESBL-producing E. coli was shown to be about 3\% in clinical samples from companion animals in the US [8,9]. ESBL urinary tract infections (UTIs) in dogs have been reported in China and Switzerland in about 5\% of samples [10,11]. In some laboratories (e.g., UK and China), there is an increasing percentage of extended-spectrum cephalosporin-resistant $E$. coli found in clinical isolates from companion animals $[12,13]$.

Thus, beyond human isolates, the global emergence and spread of extraintestinal pathogenic E. coli O25-ST131 strains in ESBL isolates has also been found in companion animals [14,15]. According to the literature, ST131 can be found in clinical isolates from dogs in many countries, including the UK [12], the US [8,16], Canada [17], Japan [18,19], China [13], Germany [20,21], Australia [5,22], France [23], and Portugal [24-26]. Human-dog co-carriage was also demonstrated in several households [16,22,27]. Two large studies screening for ST131 in clinical samples in dogs determined about a 10\% prevalence of ESBL-producing isolates [20] and 7\% for fluoroquinolone-resistant E. coli [28]. In a study from Japan [19], ST131 constituted 36\% of all clinical isolates of ESBL-producing E. coli infection among dogs and cats, and all subclones were FimH30. In comparison to FimH 30, fimH41 (clade A) and fimH22 (clade B) are usually antibiotic-susceptible alleles and are thought to be precursor subclones of FimH30. [29,30].

Few studies systematically collect rectal swabs or fecal carriage information for drug-resistant $E$. coli or ST131 in asymptomatic dogs. Moreover, the distribution of fimH type and other antibiotic-resistant genes in ST131 dog feces in Taiwan remains unclear. In this study, we investigate the prevalence of fluoroquinolone-resistant and beta-lactam-resistant $E$. coli in healthy dogs in Taiwan and determine if any risk factors, such as feeding habits or prior antibiotic use, are related to antibiotic-resistant E. coli. We also sought to study the subtypes and other antibiotic-resistant genes of the epidemic strain ST131 in asymptomatic dogs in Taiwan.

\section{Materials and Methods}

Rectal swabs from 299 dogs more than 6 months old were performed when the dogs visited the hospital for vaccinations and health exams. We collected information about sex, age, antibiotic use, and dietary habits from the owner. Dogs less than 6 months old or adopted less than 1 month prior to the study were excluded.

We used a $\mathrm{BD}^{\mathrm{TM}}$ transport tube for anal/rectal swabbing. E. coli was isolated through a conventional method, and antibiotic resistance was determined by the disk diffusion method, including resistance of cefazolin, ciprofloxacin, ceftriaxone, gentamicin, and trimethoprim/sulfamethoxazole (TMP/SMZ). ESBL confirmation followed the recommendations of the Clinical and Laboratory Standards Institute (CLSI) by using a combined-disk test for ESBL production in Enterobacteriaceae. This test consists of measuring the growth-inhibitory zones around both the cefotaxime (CTX) and ceftazidime (CAZ) disks with or without clavulanate (CA) [31].

DNA was extracted with a MasterPure ${ }^{\mathrm{TM}}$ complete DNA and RNA purification kit (Lucigen Corp., Middleton, WI, USA). Seven phylogroups were recognized (A, B1, B2, C, D, E, F) by multiplex PCR [32]. All PCR reactions were performed under the following conditions: 5 min at $95^{\circ} \mathrm{C}$ for denaturation; 25 cycles of $30 \mathrm{~s}$ at $95^{\circ} \mathrm{C}$ and $30 \mathrm{~s}$ at $59{ }^{\circ} \mathrm{C}$ (Quadruplex), $57^{\circ} \mathrm{C}$ (Group C), or $55^{\circ} \mathrm{C}$ (Group E); and $5 \mathrm{~min}$ at $72{ }^{\circ} \mathrm{C}$ for extension. The PCR product was measured with $2 \%$ agarose (Cyrusbioscience, Inc., New Taipei, Taiwan). The nine main Escherichia coli phylogroup B2 lineages involved in extra-intestinal infections were identified by the allele-specific PCR method [33]. All PCR reactions were performed under the following conditions: $4 \mathrm{~min}$ at $94^{\circ} \mathrm{C}$ for denaturation and 25 cycles of $5 \mathrm{~s}$ at $94^{\circ} \mathrm{C}, 20 \mathrm{~s}$ at $63^{\circ} \mathrm{C}$, and $5 \mathrm{~min}$ at $72{ }^{\circ} \mathrm{C}$ for extension. The PCR product was measured with $2 \%$ agarose (Cyrusbioscience, Inc., New Taipei, Taiwan).

In ESBL E. coli isolates, we performed ESBL gene screening including blaCTX-M, blaSHV, blaTEM, and blaOXA-1 by PCR using previously described methods [34]. In addition to E. coli colonization, 
we also screened for ST131 in some E. coli isolates from diseased dogs. If ST131 was found by the previous multiplex PCR, whole genome sequencing was performed. A genomic library was constructed using a Nextera XT DNA library preparation kit (Illumina, San Diego, CA, USA). We performed sequencing using an Illumina MiSeq platform with paired-end chemistry. All contigs were submitted to the CGE Finder Series (Centre for Genomic Epidemiology, Technical University of Denmark (DTU), https://cge.cbs.dtu.dk/services/).

The presence of resistance genes in the whole genome sequences and subtypes of the ST131 E. coli isolates was investigated by ResFinder and CHtyper [35].

\section{Results}

Among the 299 dogs, 26 dogs provided two isolates at collection. Fourteen dogs had no E. coli isolated when we performed the anal swab. We found 311 isolates for further antibiotic susceptibility tests and PCR studies, including a phylogenetic group and genotype study. In the antibiotic susceptibility test, there were $43.1 \%$ cefazolin-resistant and $22.1 \%$ fluoroquinolone-resistant E. coli colonies. Moreover, ESBL-producing E. coli fecal colonies were found in $9.4 \%$ of dogs. In the 28 isolates of ESBL-producing E. coli, ESBL gene can be found in blaSHV $(\mathrm{n}=7)$, blaTEM $(\mathrm{n}=2)$, bla OXA $(\mathrm{n}=3)$, blaCTX-M group one $(\mathrm{n}=19)$, group two $(\mathrm{n}=8)$ and group nine $(\mathrm{n}=9)$.

In the phylogenetic study, 279 isolates were able to be grouped by PCR. The percentage of phylogenetic groups is shown in Figure 1. B2 was the predominant group $(\mathrm{n}=84,30.1 \%)$, followed by B1 $(n=73,26.2 \%)$ and A $(n=44,15.8 \%)$.

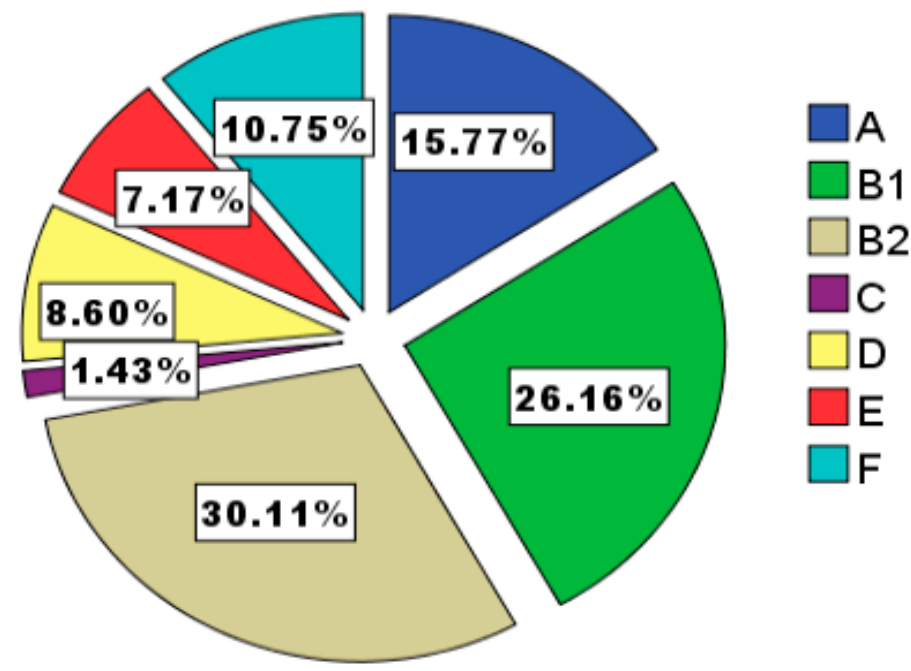

Figure 1. Phylogenetic group distribution (including group A, B1, B2, C, D, E, and F) of E. coli in the anal swabs of dogs.

Among the 84 isolates of the B2 group, further clonal complexes could be found by multiplex PCR in 71 isolates. The distributions of common sequence type (ST) complexes are shown in Figure 2. The three most predominant ST complexes were STc372, followed by STc127 and STc131.

In the analysis of the risk factors for ESBL-producing E. coli, the food habits of the animals were not different. However, the ESBL-producing group had more antibiotic exposure in the last 14 days prior to the study $(39.3 \%$ vs. $13.7 \%, p<0.05)$ (Table 1$)$. The cefazolin-resistant $E$. coli group also had higher antibiotic exposure than cefazolin-susceptible E. coli $(26.4 \%$ vs. $8.0 \%, p<0.05)$ (Table 1$)$. In the comparison between fluoroquinolone-resistant $E$. coli and fluoroquinolone-susceptible $E$. coli, the trend of antibiotic exposure in the last 14 days was similar ( $40.9 \%$ vs. $9.0 \%, p<0.05)$. The dietary habits were similar between the fluroquinolone-resistant and fluoroquinolone-susceptible groups (Table 1). Different antibiotic exposure histories were not found in the phylogenetic B2 and non-B2 groups (Table 2). 


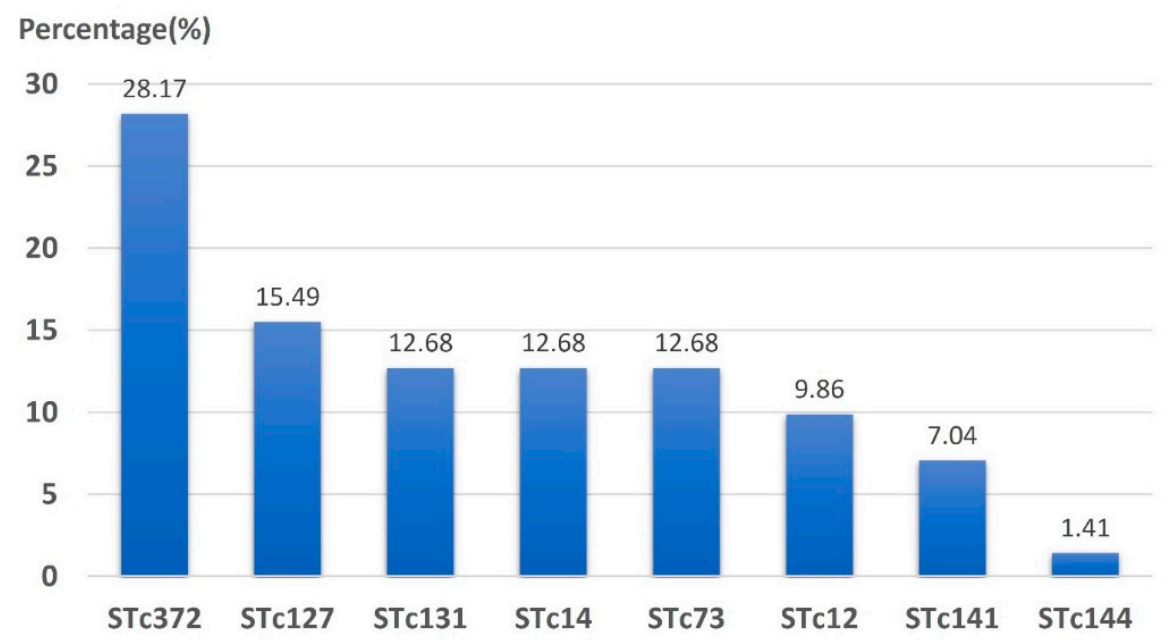

Figure 2. Sequence type, clonal complex (STc) distribution of phylogenetic group B2.

Table 1. Risk factors of antimicrobial-resistant E. coli in the fecal carriage of dogs.

\begin{tabular}{cccc}
\hline & ESBL-Producing E. coli & Non-ESBL-Producing E. coli & $p$ \\
\hline $\mathrm{N}$ & 28 & 271 & 0.562 \\
Age, years & $8.5(4.7)$ & $9.1(4.7)$ & 0.867 \\
Sex & $14.0(50.0)$ & $140(51.7)$ & 0.365 \\
Commercial pet food & $9(32.1)$ & $66(24.4)$ & 0.599 \\
Human food use & $17(60.7)$ & $178(65.7)$ & $<0.001$ \\
Recent use of antimicrobial agents & $11(39.3)$ & $37(13.7)$ & 0.819 \\
\hline $\mathrm{N}$ & Cefazolin-resistant & Cefazolin-susceptible & 0.736 \\
Age & 129 & 170 & 0.863 \\
Sex & $9.1(4.8)$ & $9.0(4.7)$ & 0.831 \\
Commercial pet food & $65(50.4)$ & $89(52.4)$ & $<0.001$ \\
Human food use & $33(25.6)$ & $42(24.7)$ & $110(64.7)$ \\
Recent use of antimicrobial agents & $85(65.9)$ & $14(8.2)$ & 0.989 \\
\hline Age & $34(26.4)$ & Ciprofloxacin-susceptible & \\
Sex & Ciprofloxacin-resistant & 233 & 0.576 \\
Commercial pet food & 66 & $9.0(4.8)$ & 0.642 \\
Human food use & $9.0(4.5)$ & $118(50.6)$ & 0.990 \\
Recent use of antimicrobial agents & $36(54.5)$ & $57(24.5)$ & $<0.001$ \\
\hline
\end{tabular}

Note: Some dogs had two E. coli isolates in their fecal specimen, and some did not provide any E. coli; ESBL extended-spectrum $\beta$-lactamases.

Table 2. Risk factors of E. coli fecal carriage of phylogenetic B2.

\begin{tabular}{cccc}
\hline & Phylogenetic B2 Carrier & Non-Phylogenetic B2 Carrier & $p$ \\
\hline N & 79 & 220 & \\
Age & $10.1(4.9)$ & $8.6(4.6)$ & 0.023 \\
Sex & $41(51.9)$ & $113(51.4)$ & 0.935 \\
commercial pet food & $20(25.3)$ & $55(25.0)$ & 0.956 \\
human food use & $55(69.6)$ & $140(63.6)$ & 0.338 \\
recent use of antimicrobial agents & $13(16.5)$ & $35(15.9)$ & 0.910 \\
\hline
\end{tabular}


A further whole genome analysis was performed on 10 ST131 isolates, including seven isolates of fecal colonization and three isolates of clinical infection. The FimH types and antibiotic-resistant genes found by Res finder and the antibiotic resistance phenotypes found via the disk diffusion method are shown in Table 3.

Table 3. The antibiotic resistance profiles (genes and phenotypes) of 7 fecal carriages of ST131 isolates and 3 clinical isolates from diseased dogs.

\begin{tabular}{|c|c|c|c|c|c|c|c|c|}
\hline $\begin{array}{l}\text { FimH } \\
\text { Type }\end{array}$ & \multicolumn{2}{|l|}{$\begin{array}{c}\text { Aminoglycoside R Gene and } \\
\text { Phenotype }\end{array}$} & \multicolumn{2}{|l|}{$\begin{array}{l}\text { TMP/SMZ R Gene and } \\
\text { Phenotype }\end{array}$} & \multicolumn{2}{|c|}{$\begin{array}{l}\text { Cephalosporin R Gene and } \\
\text { Phenotype } \\
\text { (Cefazolin, Ceftriaxone, ESBL) }\end{array}$} & \multicolumn{2}{|c|}{$\begin{array}{l}\text { Quinolone R } \\
\text { Gene and } \\
\text { Phenotype }\end{array}$} \\
\hline \multicolumn{9}{|c|}{ Fecal Carriage } \\
\hline 22 & aac(3)-IId-like, aadA12-like & $\mathrm{R}$ & sul2-like, sul3, dfrA12 & $\mathrm{R}$ & $b l a_{\mathrm{CTX}-\mathrm{M}-65}, b l a_{\mathrm{TEM}-1 \mathrm{~B}-\mathrm{like}}$ & $\mathrm{R}, \mathrm{R},+$ & QnrS1-like & $\mathrm{R}$ \\
\hline 22 & nd & S & nd & $\mathrm{S}$ & nd & S, S, - & nd & $\mathrm{S}$ \\
\hline $41 *$ & aac(3)-IId-like & $\mathrm{R}$ & sul2, dfrA14-like & $\mathrm{R}$ & $b l a_{\mathrm{CMY}-2}, b l a_{\mathrm{CTX}-\mathrm{M}-55}$ & $\mathrm{R}, \mathrm{R},+$ & QnrS1 & $\mathrm{S}$ \\
\hline 22 \# & aac(3)-IId-like, strA, strB-like & $\mathrm{R}$ & sul2-like & $\mathrm{S}$ & nd & $\mathrm{S}, \mathrm{S},-$ & nd & $\mathrm{R}$ \\
\hline $41^{\#}$ & aac(3)-IId-like, strA, strB-like & $\mathrm{R}$ & sul2-like & $\mathrm{S}$ & $b l a_{\mathrm{TEM}-1 \mathrm{~B}}$ & $\mathrm{~S}, \mathrm{~S},-$ & $\mathrm{N}$ & $\mathrm{R}$ \\
\hline 30 & aac(3)-IIa-like, aadA5 & $\mathrm{R}$ & sul1, dfrA17 & $\mathrm{R}$ & $b l a_{\mathrm{CTX}-\mathrm{M}-15}$ & $\mathrm{R}, \mathrm{R},+$ & $\operatorname{aac}\left(6^{\prime}\right) \mathrm{Ib}-\mathrm{cr}$ & $\mathrm{R}$ \\
\hline 41 & aadA5, strA, strB-like & $S$ & sul1, sul2-like, dfrA17 & $\mathrm{R}$ & $b l a_{\text {TEM-1B-like }}$ & S, S, - & nd & $\mathrm{R}$ \\
\hline \multicolumn{9}{|c|}{ Clinical isolates from diseased dogs } \\
\hline 30 & aac $\left(6^{\prime}\right)-\mathrm{Ib}-\mathrm{cr}$ & $\mathrm{S}$ & nd & $\mathrm{S}$ & $b l a_{\mathrm{CTX}-\mathrm{M}-15}$ & $\mathrm{R}, \mathrm{R},+$ & aac $\left(6^{\prime}\right)-\mathrm{Ib}-\mathrm{cr}$ & $\mathrm{S}$ \\
\hline 30 & aac $\left(6^{\prime}\right)-\mathrm{Ib}-\mathrm{cr}$ & $\mathrm{S}$ & nd & $\mathrm{S}$ & bla $a_{\text {CTX-M-15 }}$ & $\mathrm{R}, \mathrm{R},+$ & aac $\left(6^{\prime}\right)-\mathrm{Ib}-\mathrm{cr}$ & $\mathrm{R}$ \\
\hline 30 & nd & S & nd & $\mathrm{S}$ & nd & $\mathrm{R}, \mathrm{R},-$ & nd & $\mathrm{R}$ \\
\hline
\end{tabular}

Among the seven isolates of ST131 in the fecal colonies, the most predominant subtypes were FimH41 $(42.8 \%, \mathrm{n}=3)$ and FimH22 $(42.8 \%, \mathrm{n}=3)$. Moreover, FimH30 was found in only one $(14.3 \%)$ of the fecal isolates but in $100 \%$ of the three clinical isolates from dogs with infections. ESBL enzymes in the fecal colonies included CTX-M15 $(n=1)$, CTX-M55 $(n=1)$, and CTX-M65 $(n=1)$. All of the infection isolates were caused by CTX-M15-producing E. coli isolates.

\section{Discussion}

This is the first study on E. coli fecal colonization with a risk factor analysis in Taiwan. We found that recent antibiotic exposure was associated with cefazolin-resistant, fluoroquinolone-resistant, and ESBL-producing E. coli. Nearly half of the E. coli isolates were resistant to cefazolin, about $20 \%$ were resistant to fluoroquinolone, and about $10 \%$ were ESBL-producing. Among healthy dogs in France and Spain, the rate of third generation cephalosporin resistance and fluroquinolone resistance was about $18 \%$ according to the anal swab [36]. In Pakistan, the percentage of ESBL-producing E. coli isolates in dog feces was shown to be as high as $80 \%$ [37], while data from the US showed a prevalence of less than $10 \%$ in dogs [38]. Our study illustrates the challenges of emerging drug-resistant pathogens in companion animals.

The predominant B2 phylogenetic clonal complexes in our cohort were STc372 and STc127. The predominant role of ST372 in this study was similar to that of the clinical isolates from dogs in the US [39] and France [40]. In Israel, ST127 was found in ESBL E. coli from a petting zoo [41] and in infected cats from Australia [42]. In another human study in the US [43], ST127 was significantly more frequently recovered from UTI samples and was the second most common ST type in young woman with UTIs in Canada [44]. ST372 was also the second most prevalent clone and the highest patient-to-patient transmission clone in a study in rehabilitation wards in Israel [45].

Similar to previous studies, the risk factors of underlying disease conditions and the use of prior antimicrobial agents were the primary risks associated with a UTI presenting MDR (multi-drug-resistant) E. coli in dogs [5]. In our ESBL E.coli isolates, the most prevalent one was found to be CTX-M group one. In a study on the ESBL genotype in diseased cats and dogs in China, CTX-M-65 and CTX-M-15 were the most predominant CTX-M enzyme types among E. coli isolates [13]. Furthermore, in the UK and Japan, CTX-M-15, CTX-M-14, and CTX-M-55 were also found to be prevalent in clinical isolates 
from companion animals [12,18]. ST131 CTX-M-15-producing E. coli strains are common in the clinical isolates of companion animals [20]. In addition to clinical isolates from infected animals, CTX-M15 was also found in the asymptomatic fecal carriers of ST131 in our cohort. CTX-M-15, which spreads pandemically among humans, was only detected in 15\% of companion animals [46]. Other CTX-M types (CTX-M-55 and -65) were also found in our fecal colonized isolates. In a previous study of households in Sweden, humans carried identical strain of ESBL E. coli to the isolates found in household dogs, indicating a transfer between humans and dogs [47]

E. coli ST131 adapt to be so successful and is now a major global health issue in both human and companion animals [48]. This may be explained by high antimicrobial resistance without any fitness cost [48]. In our cohort, ST131 was found in about $13 \%$ of B2 isolates and about $2.3 \%$ of all healthy dogs. In another human fecal carrier study in Taiwan, ST131 was found in 3.0\% in healthy adults [49]. The percentage of ST131 carriage in the fecal carrier seems similar between humans and dogs. In a study from dogs and cats admitted to a veterinary teaching hospital in Taiwan, ST131 was the second most common ST (15.4\%) in isolates with ESBL phenotype [50]. In a previous study of household pets, the index dog's urinary tract inflection strain was found to be a prevalent human-associated variant of E. coli ST131. This suggest a host-to-host transmission of ST131 among household pets [16]. Similar to the findings for humans, the fecal E. coli colonization of ST131 in our dog cohort demonstrated that subtype FimH22 and FimH41 strains have the ability to colonize the gut. Moreover, the H30 strains displayed traits that allow extra-intestinal infection [51]. A recent study showed that $\mathrm{H} 22$ accounts for nearly all ST131 meat isolates and for about 10\% of ST131 clinical isolates [52]. In a healthy human fecal colonization study, O16-ST131 with FimH41 isolates was found to be dominant [53]. In our three isolates of Fim41, two (66\%) were serotype O16 (data not shown).

\section{Conclusions}

In our E. coli fecal carriage study, the common STs circulating among humans were also found in dog isolates. The risk factor analysis similarly showed that antibiotic use leads to multidrug-resistant E. coli colonization. Ultimately, three important subclones of the epidemic clones ST131 (Fim30, Fim22, and Fim41) were found in canine fecal carriage in Taiwan.

Author Contributions: Conceptualization, J.-W.C., H.H.H. and J.-L.W.; Data curation, H.H.H., Y.L.C. and C.-M.C.; Formal analysis, J.-W.C., S.-M.C., J.S. and J.-L.W.; Funding acquisition, H.H.H. and J.-L.W.; Investigation, Y.-L.C.; Methodology, J.-W.C., S.-M.C., J.S. and J.-L.W.; Supervision, W.-C.K.; Validation, J.-W.C., C.-M.C. and W.-C.K.; Writing-original draft, J.-W.C., H.H.H. and J.-L.W.; Writing-review \& editing, J.-W.C., H.H.H., W.-C.K. and J.-L.W. All authors have read and agreed to the published version of the manuscript.

Funding: This research was funded by The Ministry of Science and Technology, Taiwan (106-2314-B-006 -081 -MY2) and Higher Education Sprout Project, Headquarters of University Advancement at National Cheng Kung University, sponsored by the Taiwan Ministry of Education (R109-17902).

Conflicts of Interest: The authors declare no conflict of interest.

\section{References}

1. Walther, B.; Tedin, K.; Lubke-Becker, A. Multidrug-resistant opportunistic pathogens challenging veterinary infection control. Vet. Microbiol. 2017, 200,71-78. [CrossRef] [PubMed]

2. Guardabassi, L.; Schwarz, S.; Lloyd, D.H. Pet animals as reservoirs of antimicrobial-resistant bacteria. J. Antimicrob. Chemother. 2004, 54, 321-332. [CrossRef] [PubMed]

3. Teshager, T.; Dominguez, L.; Moreno, M.A.; Saenz, Y.; Torres, C.; Cardenosa, S. Isolation of an SHV-12 beta-lactamase-producing Escherichia coli strain from a dog with recurrent urinary tract infections. Antimicrob. Agents Chemother. 2000, 44, 3483-3484. [CrossRef]

4. Cummings, K.J.; Aprea, V.A.; Altier, C. Antimicrobial resistance trends among canine Escherichia coli isolates obtained from clinical samples in the northeastern USA, 2004-2011. Can. Vet. J. 2015, 56, 393-398. [PubMed]

5. Saputra, S.; Jordan, D.; Mitchell, T.; Wong, H.S.; Abraham, R.J.; Kidsley, A.; Turnidge, J.; Trott, D.J.; Abraham, S. Antimicrobial resistance in clinical Escherichia coli isolated from companion animals in Australia. Vet. Microbiol. 2017, 211, 43-50. [CrossRef] 
6. Damborg, P.; Sorensen, A.H.; Guardabassi, L. Monitoring of antimicrobial resistance in healthy dogs: First report of canine ampicillin-resistant Enterococcus faecium clonal complex 17. Vet. Microbiol. 2008, 132, 190-196. [CrossRef]

7. Weese, J.S.; Blondeau, J.M.; Boothe, D.; Breitschwerdt, E.B.; Guardabassi, L.; Hillier, A.; Lloyd, D.H.; Papich, M.G.; Rankin, S.C.; Turnidge, J.D.; et al. Antimicrobial use guidelines for treatment of urinary tract disease in dogs and cats: Antimicrobial guidelines working group of the international society for companion animal infectious diseases. Vet. Med. Int. 2011, 2011, 263768. [CrossRef]

8. Liu, X.; Thungrat, K.; Boothe, D.M. Occurrence of OXA-48 Carbapenemase and Other beta-Lactamase Genes in ESBL-Producing Multidrug Resistant Escherichia coli from Dogs and Cats in the United States, 2009-2013. Front. Microbiol. 2016, 7, 1057. [CrossRef]

9. Shaheen, B.W.; Nayak, R.; Foley, S.L.; Kweon, O.; Deck, J.; Park, M.; Rafii, F.; Boothe, D.M. Molecular characterization of resistance to extended-spectrum cephalosporins in clinical Escherichia coli isolates from companion animals in the United States. Antimicrob. Agents Chemother. 2011, 55, 5666-5675. [CrossRef]

10. Li, S.; Liu, J.; Zhou, Y.; Miao, Z. Characterization of ESBL-producing Escherichia coli recovered from companion dogs in Tai'an, China. J. Infect Dev. Ctries 2017, 11, 282-286. [CrossRef]

11. Huber, H.; Zweifel, C.; Wittenbrink, M.M.; Stephan, R. ESBL-producing uropathogenic Escherichia coli isolated from dogs and cats in Switzerland. Vet. Microbiol. 2013, 162, 992-996. [CrossRef] [PubMed]

12. Bortolami, A.; Zendri, F.; Maciuca, E.I.; Wattret, A.; Ellis, C.; Schmidt, V.; Pinchbeck, G.; Timofte, D. Diversity, Virulence, and Clinical Significance of Extended-Spectrum beta-Lactamase- and pAmpC-Producing Escherichia coli From Companion Animals. Front. Microbiol. 2019, 10, 1260. [CrossRef] [PubMed]

13. Chen, Y.; Liu, Z.; Zhang, Y.; Zhang, Z.; Lei, L.; Xia, Z. Increasing Prevalence of ESBL-Producing Multidrug Resistance Escherichia coli From Diseased Pets in Beijing, China From 2012 to 2017. Front. Microbiol. 2019, 10, 2852. [CrossRef] [PubMed]

14. Trott, D. beta-lactam resistance in gram-negative pathogens isolated from animals. Curr. Pharm. Des. 2013, 19, 239-249. [CrossRef]

15. Platell, J.L.; Johnson, J.R.; Cobbold, R.N.; Trott, D.J. Multidrug-resistant extraintestinal pathogenic Escherichia coli of sequence type ST131 in animals and foods. Vet. Microbiol. 2011, 153, 99-108. [CrossRef]

16. Johnson, J.R.; Miller, S.; Johnston, B.; Clabots, C.; Debroy, C. Sharing of Escherichia coli sequence type ST131 and other multidrug-resistant and Urovirulent E. coli strains among dogs and cats within a household. J. Clin. Microbiol. 2009, 47, 3721-3725. [CrossRef]

17. Cormier, A.; Zhang, P.L.C.; Chalmers, G.; Weese, J.S.; Deckert, A.; Mulvey, M.; McAllister, T.; Boerlin, P. Diversity of CTX-M-positive Escherichia coli recovered from animals in Canada. Vet. Microbiol. 2019, 231, 71-75. [CrossRef]

18. Maeyama, Y.; Taniguchi, Y.; Hayashi, W.; Ohsaki, Y.; Osaka, S.; Koide, S.; Tamai, K.; Nagano, Y.; Arakawa, Y.; Nagano, N. Prevalence of ESBL/AmpC genes and specific clones among the third-generation cephalosporin-resistant Enterobacteriaceae from canine and feline clinical specimens in Japan. Vet. Microbiol. 2018, 216, 183-189. [CrossRef]

19. Kawamura, K.; Sugawara, T.; Matsuo, N.; Hayashi, K.; Norizuki, C.; Tamai, K.; Kondo, T.; Arakawa, Y. Spread of CTX-Type Extended-Spectrum beta-Lactamase-Producing Escherichia coli Isolates of Epidemic Clone B2-O25-ST131 Among Dogs and Cats in Japan. Microb. Drug Resist. 2017, 23, 1059-1066. [CrossRef]

20. Ewers, C.; Grobbel, M.; Stamm, I.; Kopp, P.A.; Diehl, I.; Semmler, T.; Fruth, A.; Beutlich, J.; Guerra, B.; Wieler, L.H.; et al. Emergence of human pandemic O25:H4-ST131 CTX-M-15 extended-spectrumbeta-lactamase-producing Escherichia coli among companion animals. J. Antimicrob. Chemother. 2010, 65, 651-660. [CrossRef]

21. Ewers, C.; Bethe, A.; Stamm, I.; Grobbel, M.; Kopp, P.A.; Guerra, B.; Stubbe, M.; Doi, Y.; Zong, Z.; Kola, A.; et al. CTX-M-15-D-ST648 Escherichia coli from companion animals and horses: Another pandemic clone combining multiresistance and extraintestinal virulence? J. Antimicrob. Chemother. 2014, 69, 1224-1230. [CrossRef] [PubMed]

22. Platell, J.L.; Cobbold, R.N.; Johnson, J.R.; Heisig, A.; Heisig, P.; Clabots, C.; Kuskowski, M.A.; Trott, D.J. Commonality among fluoroquinolone-resistant sequence type ST131 extraintestinal Escherichia coli isolates from humans and companion animals in Australia. Antimicrob Agents Chemother 2011, 55, 3782-3787. [CrossRef] [PubMed] 
23. Melo, L.C.; Haenni, M.; Saras, E.; Duprilot, M.; Nicolas-Chanoine, M.H.; Madec, J.Y. Emergence of the C1-M27 cluster in ST131 Escherichia coli from companion animals in France. J. Antimicrob. Chemother. 2019, 74, 3111-3113. [CrossRef] [PubMed]

24. Belas, A.; Marques, C.; Aboim, C.; Pomba, C. Emergence of Escherichia coli ST131 H30/H30-Rx subclones in companion animals. J. Antimicrob. Chemother. 2019, 74, 266-269. [CrossRef]

25. Jones-Dias, D.; Manageiro, V.; Graca, R.; Sampaio, D.A.; Albuquerque, T.; Themudo, P.; Vieira, L.; Ferreira, E.; Clemente, L.; Canica, M. QnrS1- and Aac(6')-Ib-cr-Producing Escherichia coli among Isolates from Animals of Different Sources: Susceptibility and Genomic Characterization. Front. Microbiol. 2016, 7, 671. [CrossRef]

26. Marques, C.; Belas, A.; Franco, A.; Aboim, C.; Gama, L.T.; Pomba, C. Increase in antimicrobial resistance and emergence of major international high-risk clonal lineages in dogs and cats with urinary tract infection: 16 year retrospective study. J. Antimicrob. Chemother. 2018, 73, 377-384. [CrossRef]

27. van den Bunt, G.; Fluit, A.C.; Spaninks, M.P.; Timmerman, A.J.; Geurts, Y.; Kant, A.; Scharringa, J.; Mevius, D.; Wagenaar, J.A.; Bonten, M.J.M.; et al. Faecal carriage, risk factors, acquisition and persistence of ESBL-producing Enterobacteriaceae in dogs and cats and co-carriage with humans belonging to the same household. J. Antimicrob. Chemother. 2020, 75, 342-350. [CrossRef]

28. Platell, J.L.; Cobbold, R.N.; Johnson, J.R.; Trott, D.J. Clonal group distribution of fluoroquinolone-resistant Escherichia coli among humans and companion animals in Australia. J. Antimicrob. Chemother. 2010, 65, 1936-1938. [CrossRef]

29. Pitout, J.D.D.; Finn, T.J. The evolutionary puzzle of Escherichia coli ST131. Infect. Genet. Evol. 2020, 81, 104265. [CrossRef]

30. Pitout, J.D.D.; DeVinney, R. Escherichia coli ST131: A multidrug-resistant clone primed for global domination. F1000Research 2017, 6, F1000 Faculty Rev-1195. [CrossRef]

31. Wayne, P. Performance Standards for Antimicrobial Susceptibility Testing; Clinical and Laboratory Standards Institute: Wayne, PA, USA, 2011.

32. Clermont, O.; Christenson, J.K.; Denamur, E.; Gordon, D.M. The Clermont Escherichia coli phylo-typing method revisited: Improvement of specificity and detection of new phylo-groups. Environ. Microbiol. Rep. 2013, 5, 58-65. [CrossRef]

33. Clermont, O.; Christenson, J.K.; Daubie, A.S.; Gordon, D.M.; Denamur, E. Development of an allele-specific PCR for Escherichia coli B2 sub-typing, a rapid and easy to perform substitute of multilocus sequence typing. J. Microbiol. Methods 2014, 101, 24-27. [CrossRef] [PubMed]

34. Dallenne, C.; Da Costa, A.; Decré, D.; Favier, C.; Arlet, G. Development of a set of multiplex PCR assays for the detection of genes encoding important beta-lactamases in Enterobacteriaceae. J. Antimicrob. Chemother. 2010, 65, 490-495. [CrossRef] [PubMed]

35. Zankari, E.; Hasman, H.; Cosentino, S.; Vestergaard, M.; Rasmussen, S.; Lund, O.; Aarestrup, F.M.; Larsen, M.V. Identification of acquired antimicrobial resistance genes. J. Antimicrob. Chemother. 2012, 67, 2640-2644. [CrossRef] [PubMed]

36. Dupouy, V.; Abdelli, M.; Moyano, G.; Arpaillange, N.; Bibbal, D.; Cadiergues, M.C.; Lopez-Pulin, D.; Sayah-Jeanne, S.; de Gunzburg, J.; Saint-Lu, N.; et al. Prevalence of Beta-Lactam and Quinolone/Fluoroquinolone Resistance in Enterobacteriaceae From Dogs in France and Spain-Characterization of ESBL/pAmpC Isolates, Genes, and Conjugative Plasmids. Front. Vet. Sci. 2019, 6, 279. [CrossRef] [PubMed]

37. Abbas, G.; Khan, I.; Mohsin, M.; Sajjad Ur, R.; Younas, T.; Ali, S. High rates of CTX-M group-1 extended-spectrum beta-lactamases producing Escherichia coli from pets and their owners in Faisalabad, Pakistan. Infect. Drug Resist 2019, 12, 571-578. [CrossRef]

38. Hamilton, E.; Kruger, J.M.; Schall, W.; Beal, M.; Manning, S.D.; Kaneene, J.B. Acquisition and persistence of antimicrobial-resistant bacteria isolated from dogs and cats admitted to a veterinary teaching hospital. J. Am. Vet. Med. Assoc. 2013, 243, 990-1000. [CrossRef]

39. LeCuyer, T.E.; Byrne, B.A.; Daniels, J.B.; Diaz-Campos, D.V.; Hammac, G.K.; Miller, C.B.; Besser, T.E.; Davis, M.A. Population Structure and Antimicrobial Resistance of Canine Uropathogenic Escherichia coli. J. Clin. Microbiol. 2018, 56. [CrossRef]

40. Valat, C.; Drapeau, A.; Beurlet, S.; Bachy, V.; Boulouis, H.J.; Pin, R.; Cazeau, G.; Madec, J.Y.; Haenni, M. Pathogenic Escherichia coli in Dogs Reveals the Predominance of ST372 and the Human-Associated ST73 Extra-Intestinal Lineages. Front. Microbiol. 2020, 11, 580. [CrossRef] 
41. Shnaiderman-Torban, A.; Steinman, A.; Meidan, G.; Paitan, Y.; Abu Ahmad, W.; Navon-Venezia, S. Petting Zoo Animals as an Emerging Reservoir of Extended-Spectrum $\beta$-Lactamase and AmpC-Producing Enterobacteriaceae. Front. Microbiol. 2019, 10, 2488. [CrossRef]

42. Kidsley, A.K.; O’Dea, M.; Ebrahimie, E.; Mohammadi-Dehcheshmeh, M.; Saputra, S.; Jordan, D.; Johnson, J.R.; Gordon, D.; Turni, C.; Djordjevic, S.P.; et al. Genomic analysis of fluoroquinolone-susceptible phylogenetic group B2 extraintestinal pathogenic Escherichia coli causing infections in cats. Vet. Microbiol. 2020, 245, 108685. [CrossRef] [PubMed]

43. Matsui, Y.; Hu, Y.; Rubin, J.; de Assis, R.S.; Suh, J.; Riley, L.W. Multilocus sequence typing of Escherichia coli isolates from urinary tract infection patients and from fecal samples of healthy subjects in a college community. MicrobiologyOpen 2020, 9, 1225-1233. [CrossRef] [PubMed]

44. Fibke, C.D.; Croxen, M.A.; Geum, H.M.; Glass, M.; Wong, E.; Avery, B.P.; Daignault, D.; Mulvey, M.R.; Reid-Smith, R.J.; Parmley, E.J.; et al. Genomic Epidemiology of Major Extraintestinal Pathogenic Escherichia coli Lineages Causing Urinary Tract Infections in Young Women Across Canada. Open Forum Infect. Dis. 2019, 6, ofz431. [CrossRef]

45. Adler, A.; Gniadkowski, M.; Baraniak, A.; Izdebski, R.; Fiett, J.; Hryniewicz, W.; Malhotra-Kumar, S.; Goossens, H.; Lammens, C.; Lerman, Y.; et al. Transmission dynamics of ESBL-producing Escherichia coli clones in rehabilitation wards at a tertiary care centre. Clin. Microbiol. Infect. Off. Publ. Eur. Soc. Clin. Microbiol. Infect. Dis. 2012, 18, E497-E505. [CrossRef] [PubMed]

46. Ewers, C.; Bethe, A.; Semmler, T.; Guenther, S.; Wieler, L.H. Extended-spectrum $\beta$-lactamase-producing and AmpC-producing Escherichia coli from livestock and companion animals, and their putative impact on public health: A global perspective. Clin. Microbiol. Infect. Off. Publ. Eur. Soc. Clin. Microbiol. Infect. Dis. 2012, 18, 646-655. [CrossRef]

47. Ljungquist, O.; Ljungquist, D.; Myrenås, M.; Rydén, C.; Finn, M.; Bengtsson, B. Evidence of household transfer of ESBL-/pAmpC-producing Enterobacteriaceae between humans and dogs-A pilot study. Infect. Ecol. Epidemiol. 2016, 6, 31514. [CrossRef]

48. Downing, T. Tackling Drug Resistant Infection Outbreaks of Global Pandemic Escherichia coli ST131 Using Evolutionary and Epidemiological Genomics. Microorganisms 2015, 3, 236-267. [CrossRef]

49. Wu, P.-C.; Wang, J.-L.; Hsueh, P.-R.; Lin, P.-H.; Cheng, M.-F.; Huang, I.F.; Chen, Y.-S.; Lee, S.S.-J.; Guang-Yuan, M.; Yu, H.-C.; et al. Prevalence and risk factors for colonization by extended-spectrum $\beta$-lactamase-producing or ST 131 Escherichia coli among asymptomatic adults in community settings in Southern Taiwan. Infect. Drug Resist 2019, 12, 1063-1071. [CrossRef]

50. Huang, Y.-H.; Kuan, N.-L.; Yeh, K.-S. Characteristics of Extended-Spectrum $\beta$-Lactamase-Producing Escherichia coli From Dogs and Cats Admitted to a Veterinary Teaching Hospital in Taipei, Taiwan From 2014 to 2017. Front. Vet. Sci. 2020, 7, 395. [CrossRef]

51. Nicolas-Chanoine, M.H.; Petitjean, M.; Mora, A.; Mayer, N.; Lavigne, J.P.; Boulet, O.; Leflon-Guibout, V.; Blanco, J.; Hocquet, D. The ST131 Escherichia coli H22 subclone from human intestinal microbiota: Comparison of genomic and phenotypic traits with those of the globally successful H30 subclone. BMC Microbiol. 2017, 17, 71. [CrossRef]

52. Liu, C.M.; Stegger, M.; Aziz, M.; Johnson, T.J.; Waits, K.; Nordstrom, L.; Gauld, L.; Weaver, B.; Rolland, D.; Statham, S.; et al. Escherichia coli ST131-H22 as a Foodborne Uropathogen. mBio 2018, 9. [CrossRef] [PubMed]

53. Zhong, Y.M.; Liu, W.E.; Liang, X.H.; Li, Y.M.; Jian, Z.J.; Hawkey, P.M. Emergence and spread of O16-ST131 and O25b-ST131 clones among faecal CTX-M-producing Escherichia coli in healthy individuals in Hunan Province, China. J. Antimicrob. Chemother. 2015, 70, 2223-2227. [CrossRef] [PubMed]

(C) 2020 by the authors. Licensee MDPI, Basel, Switzerland. This article is an open access article distributed under the terms and conditions of the Creative Commons Attribution (CC BY) license (http://creativecommons.org/licenses/by/4.0/). 